\title{
SISTEM ZA AUTOMATSKO OTVARANJE I ZATVARANJE AUTOMOBILSKIH VRATA SA DETEKCIJOM PREPREKE I MERENJEM UDALJENOSTI DO PREPREKE
}

\section{AUTOMATIC DOOR OPENING AND CLOSING SYSTEM WITH OBSTACLE DETECTION AND DISTANCE MEASUREMENT}

\author{
Jovan Janjušević, Fakultet tehničkih nauka, Novi Sad
}

Oblast - ELEKTROTEHNIKA I RAČUNARSTVO

Kratak sadržaj - U radu je prikazan sistem za automatsko otvaranje i zatvaranje automobilskih vrata sa detekcijom prepreke i merenjem udaljenosti do prepreke, opisane su komponente $i$ CAN komunikacija koja se koristi.

Ključne reči: CAN komunikacija, ESP32, MCP2515, HC-SR04, ULN2003, Step motor, Arduino.

\begin{abstract}
The paper presents system for automatic opening and closing of car doors with obstacle detection and measuring distance to obstacle prevents the possibility of an car accident. The components and CAN communication used are described.
\end{abstract}

Key words: CAN communication, ESP32, MCP2515, HC-SR04, ULN2003, Step motor, Arduino.

\section{UVOD}

Zbog povećanog broja vozila na putevima, kako u svetu tako i kod nas javlja se problem nedostatka parking mesta i iz tog razloga sama parking mesta su sve uža, a vozila zbog sigurnosti sve šira.

Pomoću ovog sistema moguće je otvoriti vrata maksimalno kako bi prostor za izlaz i ulaz u vozilo bio što veći, a da pri tome ne dođe do oštećenja jednog ili drugog vozila.

U radu će biti detaljno opisana realizacija ovog sistema i moguća buduća unapređenja. Detaljno su opisane hardverske komponente i softverski deo projekta.

\section{STRUKTURA I KOMPONENTE}

\subsection{Struktura i komponente}

Senzor šalje podatke o udaljenosti prepreke na ESP koji ih obrađuje i prosleđuje poruku MCP-u (CAN modulu) koji tu poruku stavlja na CAN magistralu i započinje komunikaciju sa drugim CAN modulom.

Drugi ESP prima tu poruku i određuje maksimalni ugao pod kojim se vrata mogu bezbedno otvoriti.

Taj podatak dalje prosleđuje modulu za upravljanje motorom koji šalje signal step motoru i otvara vrata do zadatog ugla.

\section{NAPOMENA:}

Ovaj rad proistekao je iz master rada čiji mentor je bio dr Platon Sovilj, red. prof.

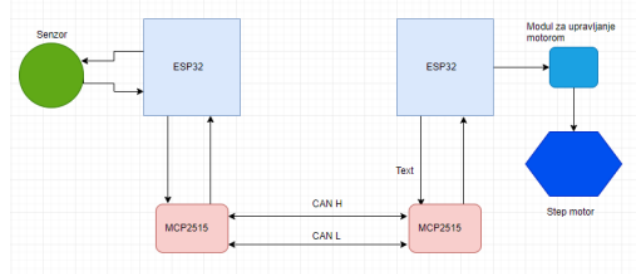

Slika 2.1 -Blok šema celog sistema

\subsection{ESP32}

Za realizaciju ovog rada korišćena su dva mikrokontrolera ESP32 sa ugrađenom WiFi i dual Bluetooth konekcijom. Sam mikrokontroler ima dva jezgra i velike performanse pa se samim tim može koristiti za razne aplikacije, svako jezgro se može posebno kontrolisati.

Srce mikrokontrolera je čip ESP-D0WDQ6, klok se može podešavati na frekvenciju od $80 \mathrm{~Hz}$ do $240 \mathrm{~Hz}$. Sam čip se napaja sa $3,3 \mathrm{~V}$ DC, a na celu pločicu se može dovesti napon od 5V DC i sama potrošnja struje u je vrlo mala i u stanju mirovanja iznosi $5 \mu \mathrm{A}$. Radna struja oko $80 \mathrm{~mA}$. SRAM memorija iznosi 512KB a flash memorija 16MB.

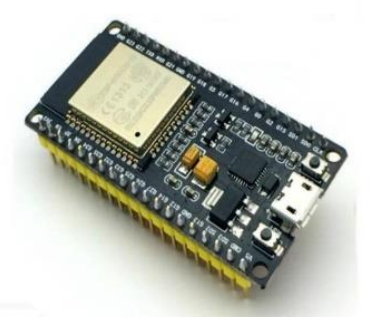

Slika $2.2-$ ESP32

\subsection{MCP2515-Arduino CAN Bus modul}

Mikrokontroleri ESP32, korišćeni u izradi ovog sistema nemaju u sebi ugrađen modul za CAN Bus komunikaciju. $\mathrm{Da}$ bi se realizovala CAN komunikacija između mikrokontrolera bilo je potrebno ubaciti eksterne CAN module.

Arduino CAN Bus modul baziran je na MCP2515 CAN kontroleru i TJA1050 transiveru. Komunikacija između ESP-a i CAN modula je SPI. Verzija sa kojom radi ova pločica je CAN V2.0B, maksimalna brzina prenosa podataka iznosi $1 \mathrm{Mb} / \mathrm{s}$ u ovom sistemu brzina je podešena na $500 \mathrm{~kb} / \mathrm{s}$. Preporučena temperature na kojoj moduo normalno funkcioniše iznosi od $-40{ }^{\circ} \mathrm{C}$ do $+80^{\circ} \mathrm{C}$. 


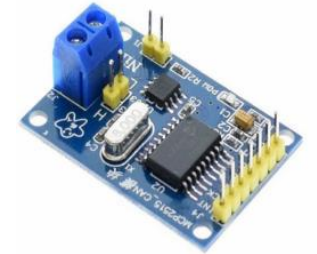

Slika 2.3-MCP 2515 CAN modul

\subsubsection{MCP2515 čip}

$\mathrm{Na}$ slici 2.5 vidimo unutrašnje blokove čipa 2515. Sam čip se sastoji od tri glavna bloka: 1. CAN modula (CAN protokoli, baferi za primanje i slanje poruka, filteri i maske); 2. Kontrolno-logički blok sa registrima; 3. Blok za SPI protocol.

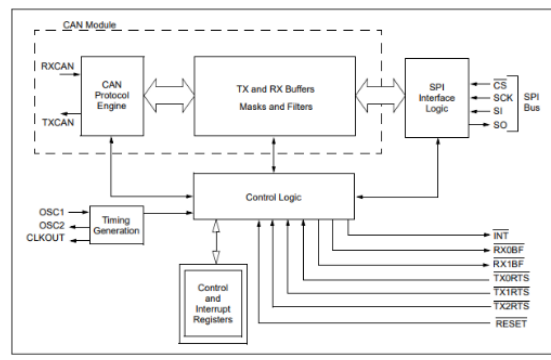

Slika 2.5-Blok šema MCP2515 čipa

1. CAN modul- blok izvršava funkcije vezane za primanje i slanje poruka preko CAN magistrale. Početak prenošenja poruke počinje iščitavanjem odgovarajućeg bafera i kontrolnog registra. Preko SPIa se zadanje komanda za čitanje ili slanje poruke preko CAN magistrale, svaka poruka se proverava $i$ propušta kroz filter da bi nakon toga bila svrstana $\mathrm{u}$ jedan od prijemnih bafera. MCP2515 sadrži dva prijemna bafera i tri bafera za slanje.

2. Kontrolno - logički blok kontroliše rad čipa i izvršava odgovarajuća podešavanja, INT pin se koristi za indikaciju kada je primljena validna poruka i upisana u bafer, provera se može još i izvršiti preko statusnih registara kojima se pristupa preko SPI interfejsa.

3. Komunikacija sa mikokontrolerom je realizovana preko SPI interfejsa

\subsubsection{TJA1050 čip}

TJA1050 je interfejs između CAN-a i fizičke magistrale (Bus). Omugućava diferencijalne mogućnosti za slanje na magistralu i diferencijalne sposobnosti za primanje CAN modula. Namenjen je za aplikacije velike brzine $u$ automotive industriji. TJA1050 je treći čip velike brzine za CAN komunikaciju fabrike Philips, prethodna dva modela su bila: PCA82C250 i PCA82C251. U odnosu na svoje prethodnike ima mnogo manju elektromagnetnu emisiju što doprinosi boljoj usklađenosti na CAN-H I CAN-L, bolje ponašanje u slučaju prekida napajanja i ne postoji režim čekanja. Napon napajanja čipa je od 4,75V do $5,25 \mathrm{~V}$.

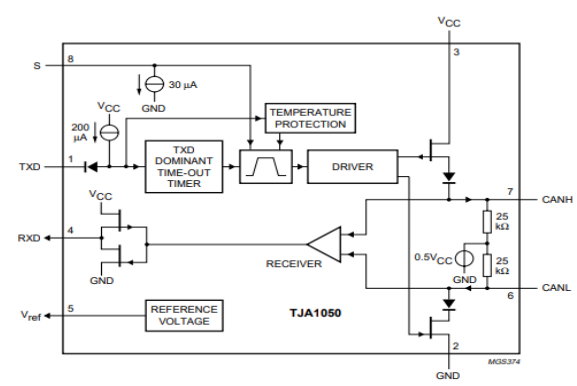

Slika 2.6-Unutrašnjost TJA1050 čipa

\subsection{Ultrazvučni sensor HC-SR04}

Na slici 2.7 prikazan je fizički izgled senzora HC-SR04.

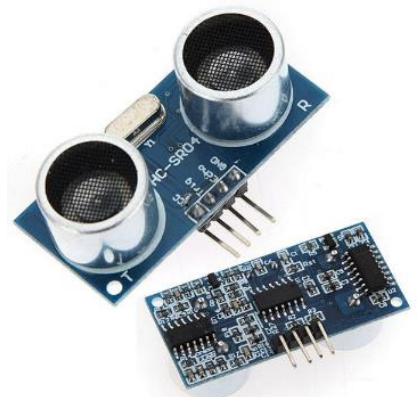

Slika 2.7-Izgled ultrazvučnog senzora HC-SR04

To je senzor za bezkontaktno merenje rastojanja. Odlikuje ga velika preciznost do $+/-3 \mathrm{~mm}$ uz vrlo malu cenu, mogućnost merenja rastojanja od $2 \mathrm{~cm}$ do $4 \mathrm{~m}$. Senzor se napaja sa 5V DC. Sa mikrokontrolera dovodimo povorku pravugaonih signala minimalnog trajanja $10 \mu \mathrm{s}$. Na mikrokontroleru softverski generišemo taj signal tako što izlazni pin stavimo u logičko stanje , 1 "u trajanju od $10 \mu \mathrm{s}$ i nakon toga ga vraćamo u logičko stanje , ,0". Signal je prikazan na slici 2.8 .

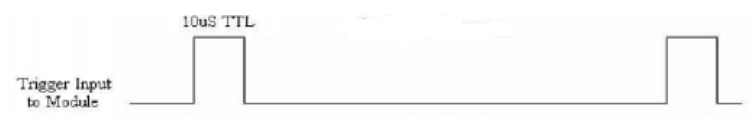

Slika 2.8- Izgled pobudnog signala koji se dovodi na pin , Trig”

Nakon primanja pobudnog signala sa mikrokontrolera, čip koji se nalazi na samoj pločici senzora generiše i emituje povorku od 8 četvrtki frekvencije $40 \mathrm{kHz}$, signal prikazan na slici 2.9. Nakon toga na prijemniku očekuje signal koji se odbio od prepreke i vratio se prema senzoru. Ukoliko je rastojanje između senzora i prepreke manje od $4 \mathrm{~m}$ signal će biti registrovan.

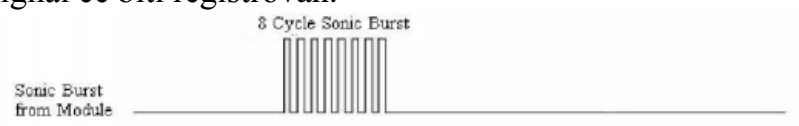

Slika 2.9-Izgled signala koji se generiše na samom senzorskom modulu

Kada se signal registruje, na pinu „Echo” se javlja četvrtka čije je vreme trajanja proporcionalno udaljenosti prepreke od senzora. Na slici 2.10 prikazan je izgled signala. 
Slika 2.10- Izgled signala koji se javlja na pinu ,Echo”

Pročitani signal, sa ulaznog pina mikrokontrolera koji je povezan sa izlaznim pinom ,Echo" sa senzora, koristimo da izračunamo udaljenost prepreke, što je prikazano $u$ jednačini 1.1 .

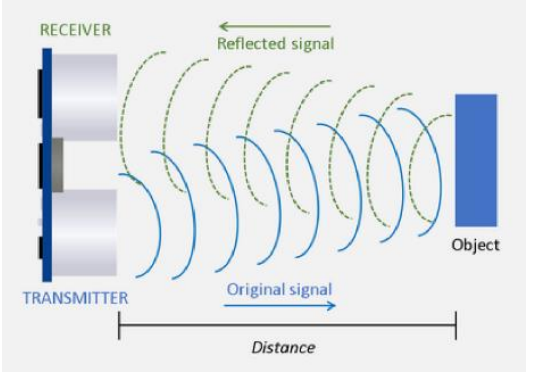

udaljenost $=$ trajanje $* 0.17$

Jednačina 1.1- Izračunavanje udaljenosti na osnovu trajanja signala

\subsubsection{ULN2003 modul za upravljanje step motorom}

Struja koju mikrokontroler može da obezbedi na svom izlazu nije dovoljna kako bi se napajali potrošači sa većom potrošnjom struje. Iz tog razloga se koriste moduli za upravljanje kao što je ULN2003 (prikazan na slici 2.13) koji u sebi sadrži sedam NPN tranzistorskih Darlington parova (drugi tranzistor povećava izlaznu struju prvog tranzistora), koji mu omogućavaju da na izlazu ostvari veći napon i struju u odnosu na ulaz.

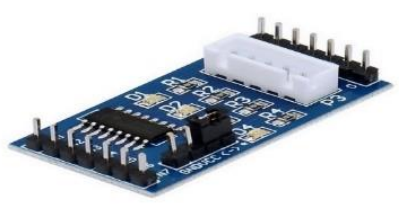

Slika 2.13-Fizički izgled modula ULN2003

Ukoliko imamo potrebu da nam je izlazna struja veća od $80 \mathrm{~mA}$ i napon veći od $5 \mathrm{~V}$ moramo kao spregu između mikrokontrolera ubaciti ULN2003. Izlazna struja po svakom pinu ULN-a iznosi 500mA, a u piku 600mA, paralelnim vezivanjem izlaza možemo dobiti veću struju. Sam moduo se povezuje preko ulaza: IN1; IN2; IN3; IN4 za sam mikrokontroler, Preporučljivo je dovesti napajanje na Vcc od $5 \mathrm{~V}$ sa eksternog napajanja, a ne sa pina mikrokontrolera kako se on ne bi oštetio usled povlačenja veće struje za pogonjenje step motora. Na samo pločici se nalaze četiri indikatorske diode pomoću kojih možemo videti koji namotaj motora je u datom trenutku uključen.

\subsubsection{Step motor 28BYJ-48}

Step motor 28BYJ-48(slika 2.14) jedan od najčešće korišćenih step motora, koristi se od DVD plejera do podešavanja položaja ogledala $u$ automobilu. Motor se sastoji od četiri namotaja, ugao svakog koraka iznosi $5,625^{\circ}$, što znači da mu je potrebno 64 koraka da napravi pun krug, zbog prenosa od 64:1, kada se upravlja polu- koračnom tehnikom maksimalan broj koraka će biti oko 4076, što znači da je izlaznom vratilu iz kućišta motora potrebno 4076 koraka kako bi se načinio pun krug. Kada motorom upravljamo sa puno-koračnom tehnikom kroz dva namotaja od ukupno četiri su u istom trenutku teče struja, kada se upravlja polu-koračnom tehnikom, prvo se pali prvi namotaj pa zatim drugi i tako redom.

Motor se napaja sa 5V DC. Prednost step motora u odnosu na klasične DC motore je u tome što su: mnogo precizniji u pozicioniranju, imaju veći obrtni moment na malim obrtajima, lako se upravlja njima i jeftini su. Obrtni moment ovog motora iznosi $34 \mathrm{mN} / \mathrm{m}$.

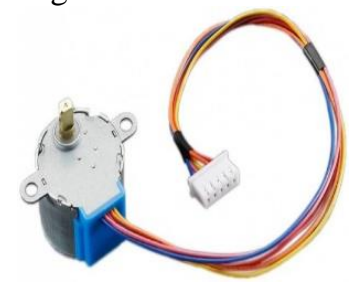

Slika 2.14-Step motor 28BYJ-48

\section{CAN BUS KOMUNIKACIJA}

CAN (Controll Area Nerwork) sistem je proizvod kompanije Robert Bosch $\mathrm{GmbH}$, Sa razvojem sistema započeto je 1983-će godine, dok je kao gotov proizvod plasiran na tržište 1986-te godine. CAN je serijski komunikacijski sistem osnovan za potrebe automotiv industrije. Zbog sve većeg broja elektronskih komponenti u vozilu, sistema komfora, sistema aktivne i pasine zaštite količina same instalacije u vozilu dostigla je svoj maksimum i javila se potreba za uvođenjem magistrale na koju će biti povezani svi sistemi i preko koje će moći međusobno da komuniciraju (slika 3.1).

CAN je dvožični komunikacioni sistem sa priključcima za otpornike na svakom kraju komunikacione linije. Obezbeđuje centralizovanu kontrolu svih sistema povezanih na magistralu, brzina prenosa podataka je ograničena na $1 \mathrm{Mb} / \mathrm{s}$. Kada neki sistem želi da pristupi magistrali, izvršava proveru da li je magistrala slobodna i tek tada šalje paket, ako se desi da više sistema pristupa magistrali $\mathrm{u}$ isto vreme, pristup će biti prvo dozvoljen sistemu sa najvišim prioritetom. CAN sistem ima ugrađen sistem za detekciju greške i mehanizam za oporavak. Prijemni čvorovi proveravaju integritet poruka tako što pregledaju CRC polja. Ako se detektuje greška, ostali čvorovi na liniji se obaveštavaju porukama o grešci.

\section{SISTEM}

\subsection{Hardver}

Na slici 4.1 vidimo fizičku implementaciju samog sistema koji je tema rada. Ceo sistem je fiksiran na plastičnu ploču, komponente su povezane pomoću žica koje su fiksirane postupkom lemljenja na pinove. Sistem se može napajati na dva načina preko mikro USB portova na mikrokontrolerima ili preko USB A kabla koji je zalemljen odole na naponski čvor i masu celog sistema. Pritiskom na crveni taster šaljemo komandu za otvaranje vrata, a pritiskom na crni taster šaljemo komandu za zatvaranje vrata. Da bi oscilacije opruge u tasteru bile otklonjene na svaki taster vezano je kolo za debouncing kao na slici 4.2. Iz razloga što step motor nema svoj početni položaj, odnosno za početni položaj uzima onaj 
položaj u kom se našao pre isključenja napajanja, dodat je mikro taster u sistem koji kada je pritisnut, motor se nalazi u početnom položaju. Kada se dovede napon napajanja, motor se automatski rotira dok ne naiđe na mikro taster.

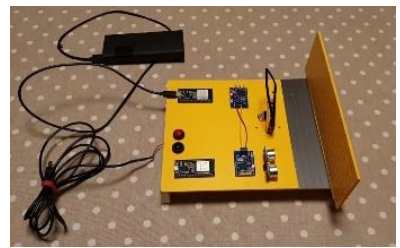

Slika 4.1- Sistem za automatsko otvaranje i zatvaranje vrata

\subsection{Softver}

Kod koji je spušten na prvi ESP zadužen je za primanje signala sa senzora HC-SR04, na osnovu primljenog signala izračunava udaljenost i stavlja je u paket zajedno sa podacima sa tastera koji definišu da li je data komanda za otvaranje ili za zatvaranje vrata.

Funkcija koda, koji je spušten na drugi ESP, jeste da prihvati poruku sa CAN magistrale, raspakuje paket i na osnovu podataka odredi ugao za otvaranje vrata i prosledi zadati smer.

\section{ARDUINO}

Arduino je zajednički naziv za familiju mikrokontrolerskih platformi, namenjenih razvoju aplikacija. Razvoj softvera je omogućen korišćenjem Open-source integrisanog razvojnog okruženja. Pisan je u programskom jeziku Java i postoji u varijantama za operativni sistem Windows, Linux i MAC OS X.

Programski jezik Arduino aplikacija koristi osnovne elemente jezika $\mathrm{C}$ i $\mathrm{C}++$.

\section{ZAKLJUČAK}

U ovom radu detaljno je objašnjen sistem za automatsko otvaranje i zatvaranje automobilskih vrata sa detekcijom prepreke i merenjem udaljenosti do prepreke, sve komponente koje su korišćene za izradu rada, kao i programsko okruženje. Detaljno je ispisan i objašnjen kod koji je napravljen za potrebe ovog sistema, U daljem radu moguće je unapređenje sistema, tako što bi se umesto ultrazvučnog senzora koristile kamere sa senzorom dubine.

\section{LITERATURA}

1.ESP32- http://www.vitaelko.com/novosti/espressifesp32-i-esp-wroom-32/

2.https://www.elecrow.com/download/esp_wroom_32 da tasheet en.pdf

3.http://ww1.microchip.com/downloads/en/DeviceDoc/M CP2515-Stand-Alone-CAN-Controller-with-SPI20001801J.pdf

4.HC-SR04- https://randomnerdtutorials.com/completeguide-for-ultrasonic-sensor-hc-sr04/

5.ULN2003-

https://www.st.com/resource/en/datasheet/uln2001.pdf 6.28BYJ-48https://components101.com/motors/28byj-48stepper-motor

7.Dogan Ibrahim: Controler Area Network

8.Arduino programsko okruženje,

http://www.elektronika.ftn.uns.ac.rs/images/Elektronika( E2)/Arduino\%20uputstvo.pdf

9.Setup petlja https://www.arduino.cc/en/Reference/Setup 10.Loop petlja

https://www.arduino.cc/en/Reference/Loop

11. https://www.allaboutcircuits.com/technicalarticles/introduction-to-can-controller-area-network/ 12.Interrupt petlja

https://www.arduino.cc/reference/en/language/functions/e xternal-interrupts/attachinterrupt/

\section{Kratka biografija}

Jovan Janjušević rođen je u Novom Sadu 1994. Diplomirao je na Fakultetu tehničkih nauka u Novom Sadu, na smeru Biomedicinsko inženjerstvo 2018. godine. 